\title{
On the Fatigue of Steel Catenary Risers
}

\author{
Nnamdi Onochie Chibueze - Chinwuba Victor Ossia* - John Umunna Okoli \\ University of Port Harcourt, Offshore Technology Institute, Nigeria
}

Steel catenary risers (SCR), though an appropriate and cost effective tool for deepwater development, are fraught with difficult fatigue challenges derived from loads due to the actions of wind, wave and current. In this study, a model SCR-AB with end-A attached to floating production, storage and offloading vessels (FPSO) and end-B anchored to the seabed was created using OrcaFlex ${ }^{\circledR}$ finite element software. Also attached to this model is a $10^{4} \mathrm{~kg} 6 \mathrm{D}$ buoy of $6 \mathrm{~m}$ height and volume $20 \mathrm{~m}^{3}$, which was fixed to the $\mathrm{SCR}$ at $900 \mathrm{~m}$ of the riser length. The various sections of the homogenous $2200 \mathrm{~m}$ long SCR pipe include $50 \mathrm{~m}$ flex joint section, $350 \mathrm{~m}$ strake length, $1300 \mathrm{~m}$ riser pipe length, and $500 \mathrm{~m}$ flowline section. Metrological ocean data, geotechnical data and SCR data were input into the model which was subjected to the Ochi-Hubble and Joint North Sea Wave Project (JONSWAP) wave spectra. Analyses to determine the influence of fatigue damage on the model was made using system simulation under both static and dynamic modes. The results for JONSWAP wave spectra showed the fatigue life of the SCR to be 1.8 years at the touch-down-point (TDP) while that of Ochi-Hubble wave spectra showed a fatigue life of 13.6 years at SCR TDP, differing by a factor of 7.5. Furthermore, the S-N curves obtained from both wave spectra corroborated an inverse relationship between Stress values $S$ and the number of stress cycles to failure $N$ on a log-log scale.

Keywords: steel catenary risers, touchdown point, Ochi-Hubble, JONSWAP

Highlights

- $\quad$ Fatigue life at SCR TDP and SCR hang-off obtained are very low, indicative of higher stresses derived from FPSO dynamics, ocean current, wave spectra, and other environmental loadings.

- There is a sharp rise in the SCR tension (mooring line effective tension) from zero at FPSO hang-off point to a maximum of $30 \times 106 \mathrm{kN}$ at $5 \mathrm{~m}$ arc length due to the reasons mentioned above.

- JONSWAP and Ochi-Hubble wave spectra used for SCR design are used to determine the SCR fatigue life, tension, cost, etc. by the oil and gas industry operators.

- JONSWAP wave spectrum is often used by engineers for SCR designs in the Gulf of Guinea leads to overdesign with the attendant cost (time, material, logistics, etc.) and is compared to Ochi-Hubble wave spectrum, which is closer to the real-time wave spectra.

\section{INTRODUCTION}

\subsection{Background}

Oil \& gas exploration and production activities in deep waters of the Gulf of Mexico, Gulf of Guinea, Brazil, and the North Sea have increased dramatically in recent years, nearly doubling, compared to the activities of a decade ago [1]. Regardless of the floating platform concept adopted for many offshore field development activities, there is always need for a riser system, which has played a massive role as offshore infrastructure [2]. There is, therefore, a need to ensure that the integrity of riser systems is not compromised; that is, ensuring high fatigue life in performance. In West African deepwater, for example, steel catenary risers (SCR) are commonly used because of the prevalent conditions, though fatigue remains a challenge [3]. SCR is a costeffective alternative for oil and gas export and for water injection lines on deepwater fields, where large-diameter flexible risers present technical and economic limitations [4]. Among the riser concepts (e.g. flexible risers, hybrid risers), SCRs have enjoyed widespread acceptability for deep and ultra-deepwater applications in recent years. This is due to their relatively low cost, conceptual simplicity, significant structural capacity, and ease of fabrication and installation. However, their fatigue response has been a concern to the industry, especially in West Africa [3]. SCR fatigue damage can be caused by vortex-induced vibration (VIV) and vortex-induced motion (VIM) at the touch-down-point (TDP) [3]. Fatigue of SCR at TDP has been one of the most challenging problems in deep water due to interactions with the seabed [5]. The fatigue damage induced by VIV and VIM can be fatal to the riser [6].

\subsection{Wave Environment}

Harsh environments influence motions of floating platforms, which in turn affect the riser system dynamics. For instance, the application of SCRs with semi-submersibles or floating production, storage and offloading vessels (FPSOs) in harsh deepwater environments presents design challenges due to large wave-induced motions on the platform, and large vessel offsets caused by wind, currents, and slow-drift 
wave motions. The resulting large heave motions of the vessel cause buckling and fatigue-related issues of the riser at TDP [7]. The wave spectra adopted in SCR design becomes crucial. The two-parameter Pierson-Moskowitz wave spectrum (Eqs. (1) and (2)) is recommended by the American Bureau of Shipping [8] for an open ocean, such as the Atlantic.

$$
S_{\eta}(\omega)=\frac{5 H_{s}^{2} \omega_{p}^{4}}{16 \omega^{5}} \exp \left[-\frac{5}{4}\left(\frac{\omega_{p}}{\omega}\right)^{4}\right]
$$

or,

$$
S_{\eta}(\omega)=\frac{H_{s}^{2} \omega_{p}^{4}}{4 \pi \omega^{5}}\left(\frac{2 \pi}{T_{s}}\right)^{4} \exp \left[-\frac{1}{\pi}\left(\frac{2 \pi}{T_{s}}\right)^{4} \omega^{-4}\right] .
$$

The Joint North Sea Wave Project (JONSWAP) spectrum (Eqs. (3) and (4)) modified the PiersonMoskowitz spectrum [9] above to account for regions with geographical boundaries the limit the fetch in wave generation.

$S_{\eta}(\omega)=\frac{5 H_{s}^{2} \omega_{p}^{4}}{16 \omega^{5}} \exp \left[-\frac{5}{4}\left(\frac{\omega_{p}}{\omega}\right)^{4}\right] \gamma^{a}(1-0.287 \ln \gamma)$,

where: $a=\exp \left[-\frac{\left(\omega-\omega_{p}\right)^{2}}{2 \sigma^{2} \omega_{p}^{2}}\right]$ and

$\sigma=\left\{\begin{array}{ll}0.07 & \text { for } \omega \leq \omega_{p} \\ 0.09 & \text { for } \omega>\omega_{p}\end{array}\right.$.

Factor $\quad(1-0.287 \ln \gamma)$ limits JONSWAP application since the spectral value is zero for $\gamma=32.6$; in which case,

$$
S_{\eta}(\omega)=\frac{\alpha g^{2}}{\omega^{5}} \exp \left[-\frac{5}{4}\left(\frac{\omega_{p}}{\omega}\right)^{4}\right] \gamma^{a} .
$$

To cover the variety of wave shapes associated with swell, storm growth and decay, the six-parameter Ochi-Hubble wave spectrum (Eq. (5)) was proposed [10].

$$
\begin{gathered}
S_{\eta}(\omega)=\frac{1}{4} \sum_{j=1}^{2} \frac{\left(\frac{4 \lambda_{j}+1}{4} \omega_{p j}^{4}\right)}{\Gamma\left(\lambda_{j}\right)} \times \frac{H_{s j}^{2}}{\omega^{4 \lambda_{j}+1}} \times \\
\exp \left(\left(-\frac{4 \lambda_{j}+1}{4}\right)\left(\frac{\omega_{p j}}{\omega}\right)^{4}\right) .
\end{gathered}
$$

where $j=1,2$ stands for the swell (lower) and wind-sea (higher) frequency components. The six parameters $H_{s 1}, H_{s 2}, \omega_{p 1}, \omega_{p 2}, \lambda_{1}$, and $\lambda_{2}$ are determined numerically to minimize errors.

\subsection{Governing Equations}

The governing equations that run the OrcaFlex [11] to [13] algorithm include Newton's Second Law, Morrison, Navier-Stokes and catenary equations.

\subsubsection{Newton's Second Law of Motion;}

Newtonian force $F$ is the sum of the inertia, damping (viscous) and elastic force-components as in Eq. (6):

$$
F=M a+C v+k x
$$

\subsubsection{Morrison Equation}

In the Morrison equation, fluid force $F$ is the sum of the Froude-Krylov force $F_{F K}$, hydrodynamic force $F_{H}$ and the drag force $F_{D}$.

$$
F=\rho V \dot{u}+\rho C_{a} V(\dot{u}-\dot{v})+\frac{1}{2} \rho C_{d} A(u-v)|u-v| .
$$

On simplifying, the fluid force becomes equal to the sum of the inertia force and drag-force.

$$
F=\left(\Delta a_{w}+C_{a} \Delta a_{r}\right)+\frac{1}{2} \rho C_{d} A V_{r}\left|V_{r}\right|
$$

\subsubsection{Navier-Stokes Equation}

Fluid inertia is equal to the sum of the pressure gradient, viscous force and body force.

$$
\begin{aligned}
& \rho\left(\frac{\partial v}{\partial t}+u \frac{\partial v}{\partial x}+v \frac{\partial v}{\partial y}+w \frac{\partial w}{\partial z}\right)= \\
&=-\frac{\partial p}{\partial y}+\mu\left(\frac{\partial^{2} v}{\partial x^{2}}+\frac{\partial^{2} v}{\partial y^{2}}+\frac{\partial^{2} v}{\partial z^{2}}\right)+F_{y} \\
& \rho\left(\frac{\partial w}{\partial t}+u \frac{\partial w}{\partial x}+v \frac{\partial w}{\partial y}+w \frac{\partial w}{\partial z}\right)= \\
&=-\frac{\partial p}{\partial z}+\mu\left(\frac{\partial^{2} w}{\partial x^{2}}+\frac{\partial^{2} w}{\partial y^{2}}+\frac{\partial^{2} w}{\partial z^{2}}\right)+F_{z} \\
& \rho\left(\frac{\partial w}{\partial t}+u \frac{\partial w}{\partial x}+v \frac{\partial w}{\partial y}+w \frac{\partial w}{\partial z}\right)= \\
&=-\frac{\partial p}{\partial z}+\mu\left(\frac{\partial^{2} w}{\partial x^{2}}+\frac{\partial^{2} w}{\partial y^{2}}+\frac{\partial^{2} w}{\partial z^{2}}\right)+F_{z}
\end{aligned}
$$




\subsubsection{Catenary Equation}

Steel catenary risers being pipelines suspended between a production platform and the seabed adopts an approximate catenary shape, defined by Eq. (12).

$$
y=\frac{H}{w}\left[\cosh \left(w \frac{x}{H}\right)-1\right] .
$$

where $w$ is weight per unit length of riser and $H$ is a constant representing horizontal component of tension.

\section{MATERIALS AND METHODS}

To study the influence of fatigue in SCR adequately, two wave application modes (Ochi-Hubble wave spectra and JONSWAP wave spectra) were adopted using Orcina OrcaFlex software. The software quality assurance is based on the requirements of BS 5750 , 5887, and 5515, and on Defence Standard 00-16. Its validation checks include checking the program against mathematical theory, the real world, and against other institutional computer programs.

Larsen [14] reported results from static and dynamic analyses of standard flexible riser systems performed by eleven different institutions using their in-house software. OrcaFlex developers took part in the major comparison of flexible riser programs initiated by the International Ship and offshore Structures Congress (ISSC) "Slender Marine Structures" committee. The study contains a complete description of the test cases and results that provide a benchmark test for users and programmers of computer code for flexible riser analysis. The results showed good agreement between OrcaFlex and other established programs with a $10 \%$ to $15 \%$ coefficient of variation.

A large-scale test has been carried out in Lake Pend Oreille under a joint industry project by scientific marine services (SMS) [15] for PMB Engineering; Australia. OrcaFlex results showed very close agreement with the test results, including details of SCR behaviour at touchdown. A major validation exercise was carried out to compare OrcaFlex with model test results obtained from a joint industry project [16]. Good agreement was obtained.

In this study, an SCR [17] and [18] comprising a line with the end-A of the riser attached to the FPSO and end-B anchored to the seabed as in Fig. 1 is modelled by carrying out the following tasks using the OrcaFlex post-processor software:

a) Set the SCR line length to be 2,200 $\mathrm{m}$ and as a homogenous pipe with flex joint, strake, riser pipe and flowline lengths modelled on the line (in that order) with the height of $1000 \mathrm{~m}$ set above the seabed with an azimuth angle of $180^{\circ}$.

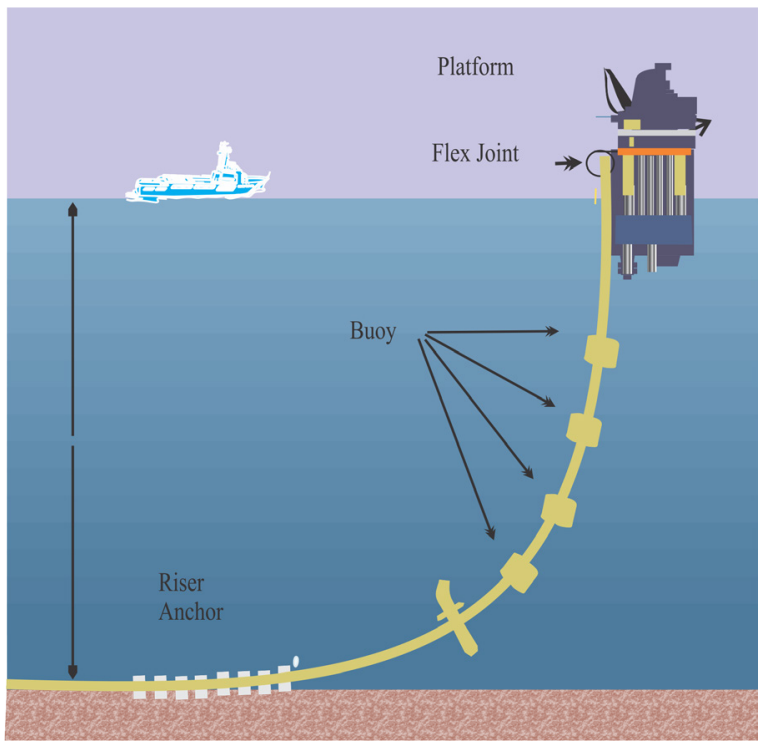

Fig. 1. Typical steel catenary riser between an FPSO and seabed

b) A $6 \mathrm{D}$ buoy is modelled and anchored onto the SCR-line.

c) The design parameters and environmental properties, which included the wave train of both Ochi-Hubble, a two parameter wave spectra that fully describes the typical sea state (valid for the swell and wind-sea conditions) of the Gulf of Guinea and that of JONSWAP were inputs in the different cases.

d) The line modelled as a riser is given real life data-values. Typical SCR data imputed to this study include: pipe of outer diameter 273.1 $\mathrm{mm}$, inner diameter $205.7 \mathrm{~mm}$, and thickness $67.4 \mathrm{~mm}$, density $7850 \mathrm{~kg} / \mathrm{m}^{3}$, elastic modulus $200 \mathrm{GPa}$, second moment of inertia $8.67 \times 10^{-5}$, mass per unit length $128.2 \mathrm{~kg} / \mathrm{m}$, bending stiffness $3.27 \times 10^{6} \mathrm{kN}$, axial stiffness $1.73 \times 10^{4}$ $\mathrm{kN}$, torsional stiffness $10 \mathrm{kNm}^{2} / \mathrm{rad}$, design life 20 years, bulk modulus $160 \mathrm{GPa}$, yield strength $483 \mathrm{MPa}$, tensile strength $562 \mathrm{MPa}$, kinematic viscosity $1.35 \times 10^{-6} \mathrm{~m}^{2} / \mathrm{s}$; and the SCR-contents, which is a crude oil of density $800 \mathrm{~kg} / \mathrm{m}^{3}$ and flow rate of $0.1 \mathrm{~kg} / \mathrm{s}$.

e) Global analysis: This describes the overall static and dynamic structural behaviour of the riser by exposing the system to a stationary environmental loading condition [19]:

- Static analysis investigates the equilibrium position of the model without considering 
environmental forces, weight, buoyancy and drag forces. After running the static analysis of this model, there was a static convergence for the model after a maximum of 100 iterations.

- The dynamic analysis is a time simulation of the SCR-model motion for a specified period, starting from the static analysis position. The real life environment data for current, wind and seabed conditions were used as inputs. Typical environment data used as input parameters in this study include: (i) metrological Ocean data for 100 years return period: significant wave height $4 \mathrm{~m}$, most probable maximum wave height $7.8 \mathrm{~m}$, crest of maximum individual wave $4.5 \mathrm{~m}$, peak spectral period $15.5 \mathrm{~s}$, mean zero crossing $7.17 \mathrm{~s}$, mean wave direction $189^{\circ}$, (ii) wind data $10 \mathrm{~min}$ wind speed $20.4 \mathrm{~m} / \mathrm{s}$, wind direction 180 Set the SCR line length to be $2,200 \mathrm{~m}$ and as a homogenous pipe with flex joint, strake, riser pipe and flowline lengths modelled on the line (in that order) with the height of $1000 \mathrm{~m}$ set above the seabed with an azimuth angle of $180^{\circ}$, (iii) current data: current speed (below $1000 \mathrm{~m}$ depth) 0.15 , surface directions $180^{\circ}$, (iv) sea water data: sea surface temperatures $25^{\circ} \mathrm{C}$, near-bed sea temperatures 4 ${ }^{\circ} \mathrm{C}$, sea water density $1025 \mathrm{~kg} / \mathrm{m}^{3}$, depth of water $1000 \mathrm{~m}$, (v) seabed data: soil friction coefficient 0.45 (nonlinear soil model was adopted). In running this dynamic analysis, the simulation time was first set at $16 \mathrm{~s}$ and observed before being run for $3 \mathrm{~h}$, the severest sea state in the Gulf of Guinea.

f) Fatigue analysis was carried out on the SCR model for both Ochi-Hubble and JONSWAP wave spectra for comparison. Before the fatigue analysis was performed, a set of Orcaflex simulation files that model the system was prepared under possible real-time load conditions. This load case was assigned an exposure level of 20 years $(175,200 \mathrm{~h})$ riser design life.

\section{RESULTS AND DISCUSSION}

\subsection{Fatigue Life - Arc Length Analysis}

From Fig. 2 based on the JONSWAP wave spectrum, it can be observed that:

- hang-off fatigue life, HOFL is 10 years;

- fatigue life range, FL; 500 years $<\mathrm{FL}<5,000$ years;

- $\quad$ TDP fatigue life, TDPFL $=1.8$ years at $1828.8 \mathrm{~m}$;

- maximum fatigue life beyond TDP $\mathrm{FL}_{\max }=$ 10,000 years.
From Fig. 3, based on Ochi-Hubble wave spectrum, it can be observed that:

- $\quad$ hang-off fatigue life; $\mathrm{HOFL} \approx 7$ years;

- fatigue life range, FL; 100 years $<\mathrm{FL}<5,000$ years;

- $\quad$ TDP fatigue life; TDPFL $=13.6$ years at 1828.8

$\mathrm{m}$;

- maximum fatigue life beyond TDP $\mathrm{FL}_{\max }=$ 10,000 years.

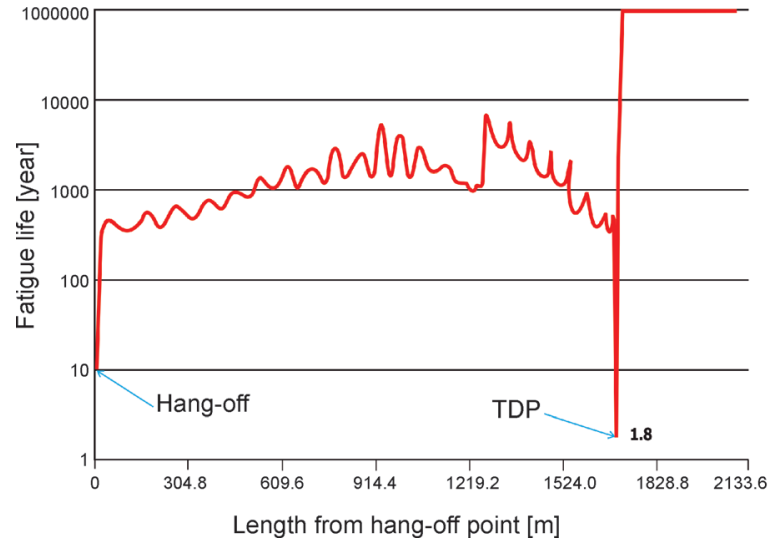

Fig. 2. Fatigue life versus SCR length from hang-off point in JONSWAP wave spectra

From Fig. 2, the fatigue life of the SCR when subjected to stress due to environmental loadings is 1.8 years, or approximately 2 years, which is very low. Low fatigue life at the SCR TDP zone is indicative of severe fatigue damage therein. From Fig. 3, the SCR fatigue life is showing a high value of 13.6 years, or approximately 14 years, though less than the proposed 20 -year design life. However, Figs. 2 and 3 show that the least fatigue life is observed in the SCR hangoff and TDP section. Hence, from Figs. 2 and 3, the fatigue life of SCR in Ochi-Hubble wave spectra is 7.5 times that of SCR fatigue life in JONSWAP wave spectra. This implies that the common practice of SCR designs based on JONSWAP wave spectrum applied in the Gulf of Guinea, where the real-time wave pattern follows the Ochi-Hubble spectra is an overdesign and the cost implication is of order 7.5 high. Figs. 2 and 3 showed the same order of fatigue life beyond TDP arc length. The low hang-off fatigue life is corroborated by the sharp rise in SCR tension from $(0 \mathrm{~m},-30 \mathrm{E} 6$ $\mathrm{kN})$ through $(2.5 \mathrm{~m}, 0 \mathrm{kN})$ to $(4.5 \mathrm{~m}, 29 \mathrm{E} 6 \mathrm{kN})$ along the SCR arc length in Fig. 4. 


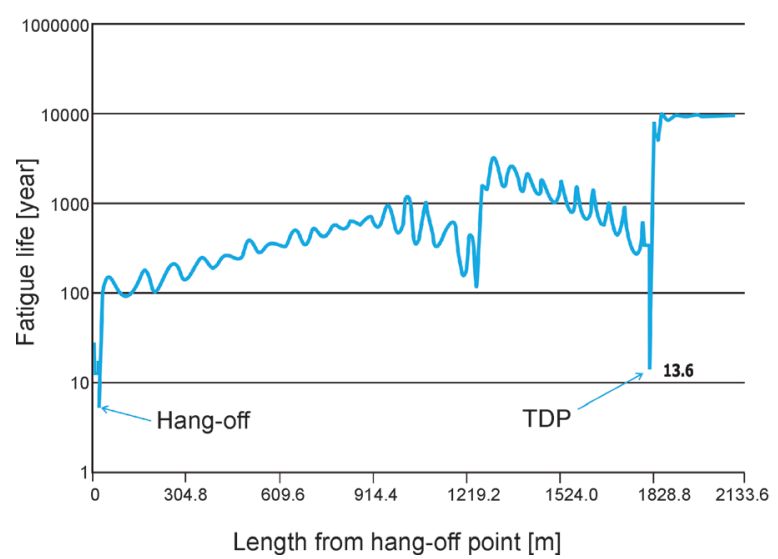

Fig. 3. Fatigue life versus SCR length from hang-off point in OchiHubble wave spectra

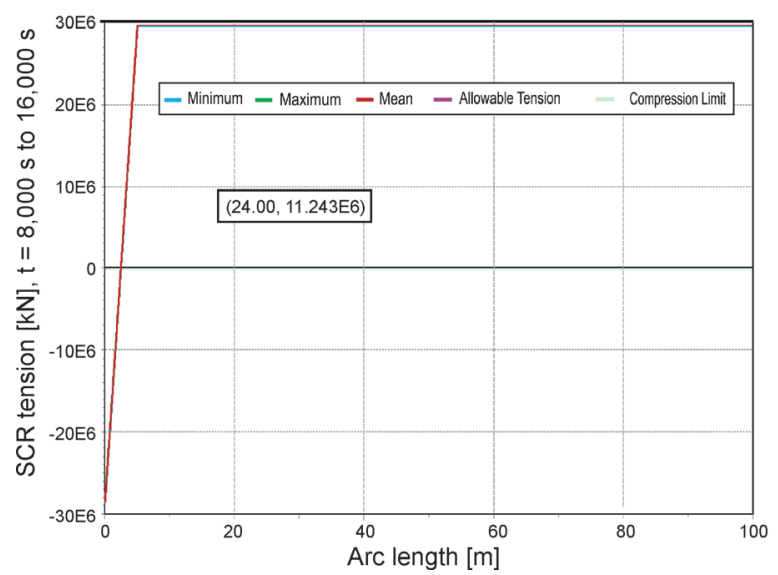

Fig. 4. SCR tension versus arc length curve

\subsection{Stress (S) - Cycles (N) to Failures}

The $S$ - $N$ curves in Figs. 5 and 6 showed that higher stress values $(S)$ caused a lower number of cycles to failure $(N)$, that is, lower endurance limits.

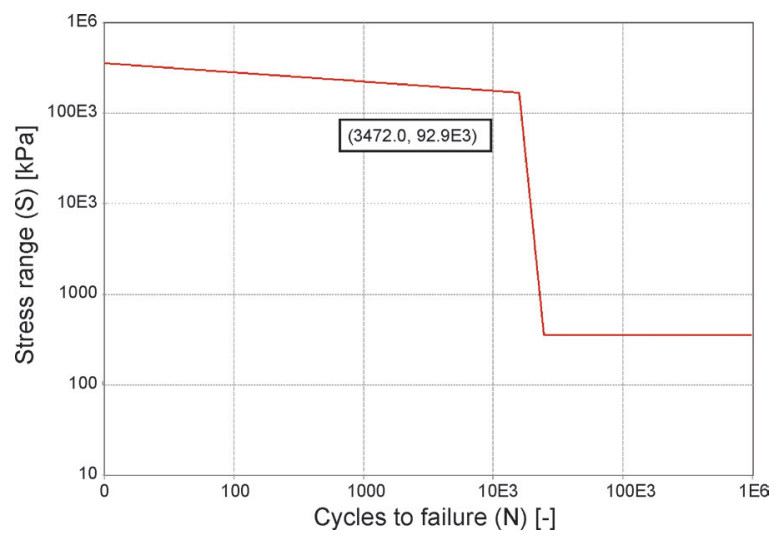

Fig. 5. Stress $S$ versus cycles to failure $N$ curve for SCR in JONSWAP wave spectra
The fall rate of stress with respect to cycles is higher with the JONSWAP spectra than the OchiHubble spectra. Comparing the slopes of the $S-N$ curves, it can be observed that the fall-rate for JONSWAP spectra is almost of order $>100$ on a log$\log$ scale relative to the Ochi-Hubble spectra. This implies that when the stresses due to environmental loading vary, it will have an effect on the riser life before failure.

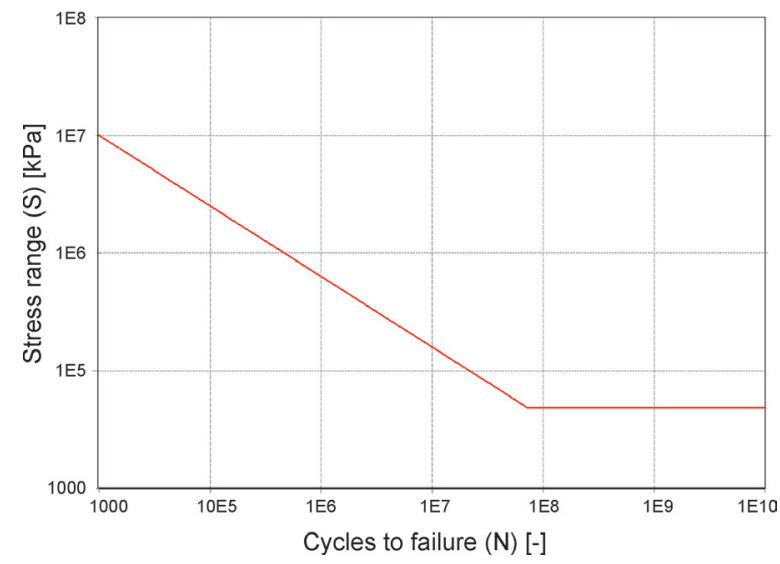

Fig. 6. Stress $S$ versus cycles to failure N curve for SCR in OchiHubble wave spectra

\section{CONCLUSION}

Using an SCR model in Ochi-Hubble wave spectra gives a higher fatigue life than JONSWAP spectra, which are often used by design companies. With a higher SCR fatigue life in Ochi-Hubble wave spectra, there is no overdesign since it thoroughly describes the actual sea state in the Gulf of Guinea.

SCR modelled in JONSWAP wave spectra gave a misrepresentation of the SCR fatigue life leading to overdesign, which implies high cost both on the side of multinational companies and contractors.

Stress variations due to environmental loading contributed immensely to SCR fatigue damage.

The high tension observed at the SCR hang-off, close to the FPSO, with both wave-spectra can be attributed to the combined action of waves, wind and current, as well as, FPSO heavy motion.

\section{NOMENCLATURE}

$\begin{array}{ll}A & \text { drag area, }\left[\mathrm{m}^{2}\right] \\ C & \text { viscosity damping factor, [Ns/m] } \\ C_{a} & \text { added mass coefficient of body } \\ C_{d} & \text { drag coefficient for the body } \\ F_{x, y, z} & \text { body force in } x, y, z \text { directions, }\left[\mathrm{N} / \mathrm{m}^{3}\right] \\ F & \text { fluid force, [N] }\end{array}$

$A \quad$ drag area, $\left[\mathrm{m}^{2}\right]$

$C \quad$ viscosity damping factor, $[\mathrm{Ns} / \mathrm{m}]$

$C_{a} \quad$ added mass coefficient of body

$C_{d} \quad$ drag coefficient for the body

$F \quad$ fluid force, $[\mathrm{N}]$ 
$H_{s} \quad$ significant wave height, $[\mathrm{m}]$

$M \quad$ mass, $[\mathrm{kg}]$

$P$ pressure, $[\mathrm{Pa}]$

$\mathrm{S}_{\eta} \quad$ wave spectral density, $\left[\mathrm{m}^{2} / \mathrm{Hz}\right]$

$T_{S} \quad$ average zero up-crossing period, [s]

$\mathrm{V}$ volume, $\left[\mathrm{m}^{3}\right]$

$V_{r} \quad$ fluid velocity relative to body, $[\mathrm{m} / \mathrm{s}]$

a acceleration, $\left[\mathrm{m} / \mathrm{s}^{2}\right]$

$a_{r} \quad$ fluid -body relative acceleration, $\left[\mathrm{m} / \mathrm{s}^{2}\right]$

$a_{w} \quad$ fluid acceleration rel. to earth, $\left[\mathrm{m} / \mathrm{s}^{2}\right]$

$g$ acceleration due to gravity, $\left[\mathrm{m} / \mathrm{s}^{2}\right]$

$j \quad$ integer counter

$k \quad$ stiffness, $[\mathrm{N} / \mathrm{m}]$

$u, v, w \quad x, y, z$ axis velocity components, $[\mathrm{m} / \mathrm{s}]$

$t$ time, [s]

$\omega \quad$ circular frequency of the wave, $[\mathrm{rad} / \mathrm{s}]$

$\omega_{p} \quad$ peak frequency for peak spectrum; $[\mathrm{rad} / \mathrm{s}]$

$\gamma \quad$ peaked-ness parameter (1 to 7).

$\alpha \quad$ parameter

$\rho$ density, $\left[\mathrm{kg} / \mathrm{m}^{3}\right]$

$\mu \quad$ dynamic viscosity, $[\mathrm{Pa} \cdot \mathrm{s}]$

$\Delta \quad$ Mass of fluid displaced by body, $[\mathrm{kg}]$

$\lambda \quad$ Ochi-Hubble's parameters $5 \& 6$

\section{REFERENCES}

[1] Song, R., Stanton, P. (2007). Deepwater tieback SCR, unique design challenges and solutions. Offshore Technology Conference, paper OTC-18524-MS Houston D0I:10.4043/18524-MS.

[2] Lim, F. (2006). Installation of risers in deepwaters. 4th Petromin Deepwater and Subsea Technology Conference and Exhibition, Kuala Lumpur.

[3] Song, R., Stanton, P. (2009). Advances in deepwater steel catenary riser technology state of art: Part II-Analysis. ASME 28th International Conference on Ocean, Offshore and Arctic Engineering, Honolulu, p. 285-296, D0l:10.1115/OMAE200979405, DOI:10.1115/OMAE2009-79405.

[4] Bai, Y., Bai, Q. (2010). Handbook of Subsea Structural Engineering, 5th Edition, Gulf Professional Publishing, Burlington, p. 847-849.

[5] Li, F.Z., Low, Y.M. (2012). Fatigue reliability analysis of a steel catenary riser at the touchdown point incorporating soil model
Uncertainties. Applied Ocean Research, vol. 38, p. 100-110, DOI:10.1016/j.apor.2012.07.005.

[6] Bai, Y. (2001). Pipelines and Risers, vol. 3. Elsevier Ocean Engineering Books Series, Bhattacharya, R, McCormick, M.E. (eds.), Elsevier Sciences Limited, Kidlington, p. 84-110.

[7] Xia, J. (2009). Weight - Optimised Steel Catenary Risers and their Application in Harsh Deepwater Environment, PhD Thesis, University of Strathclyde, Strathclyde.

[8] American Bureau of Shipping (2010). Guide for SpectralBased Fatigue Analysis for Floating, Production, Storage and Offloading (FPSO) Installations, update 2014, p. 8-12, Houston.

[9] Vyzikas, T. (2014). Application of Numerical Models and Codes. A Best Practice Report prepared as part of the MERIFIC Project - Marine Energy in Far Peripheral and Island Communities (MERIFIC), University of Plymouth, Plymouth, $p$. 56-60.

[10] Ochi, M.K., Hubble, E.N. (1976). Six-Parameters Wave Spectra. Coastal Engineering Proceedings, p. 301-328.

[11] Orcina Ltd (2013). OrcaFlex version 9.7. Software Technical Specification. Ulverston, Cumbria.

[12] Orcina Ltd (2013). Orcina Orcaflex, retrieved from: http://www. orcina.com/SoftwareProducts/OrcaFlex/index.php, accessed on 2013-12-22.

[13] Orcina Ltd (2013). OrcaFlex Manual: Version 9.7a. Orcina, Ulverston, Cumbria.

[14] Larsen, C.M. (1992). Flexible riser analysis - comparison of results from computer programs. Marine Structures, vol. 5, no. 2-3, p. 103-119, Dol:10.1016/0951-8339(92)90024-J.

[15] Scientific Marine Services, Inc (1998). Highly Compliant Riser Large Scale Model Test Joint Industry Project Data Reduction and Report SMS Project 97-504 PMB Engineering, retrieved from: http://www.bsee.gov/Technology-andResearch/Technology-Assessment-Programs/Reports/300399/305AB/, accessed on 2013-12-21.

[16] Hartnup, G.C., Airey, R.G., Fraser, J.M., (1987). Model basin testing of flexible marine risers. Proceedings of the $6^{\text {th }}$ International Offshore Mechanics and Arctic Engineering Symposium \& Exhibition, Houston.

[17] Bai, Y., Bai, Q. (2005). Subsea Pipelines and Risers, (1st ed.). Elsevier, Amsterdam.

[18] Bai, Y., Bai, Q. (2012). Subsea Engineering Handbook. Gulf Professional Publishers (Elsevier), Waltham.

[19] DNV-OS-F201 (2010). Dynamic Risers, offshore standard. Det Norske Veritas, Oslo. 